\title{
Improvement of geotechnical properties of clayey soil with saw dust ash stabilization
}

\author{
Khaizal Jamaluddin ${ }^{1}$, and Reza Pahlevi Munirwan ${ }^{1 *}$ \\ 1Department, of Civil Engineering, Universitas Syiah Kuala, Jl. Tgk. Syech Abdur Rauf No. 7 \\ Banda Aceh, Aceh 23111, Indonesia
}

\begin{abstract}
Rapid urbanization and construction are driving up the consumption of cement and aggregate used in building construction. However, the manufacture of cement and concrete boosts carbon dioxide emissions and depletes the supply of natural aggregates. As a result, alternative materials for building construction are required. A replacement material, saw dust ash (SDA), is obtained from woodfired power stations, pulp, paper mills, and other wood-burning factories. However, the SDA manufacturing sector necessitates enormous tracts of land in rural locations. As a result, some wood waste is sprinkled throughout the open land, while others are burned in incinerators, contributing to air pollution, a significant environmental issue. The purpose of this study is to provide a brief overview of the practical usage of SDA as a substitute material in the building sector, especially for soil stabilization. The article provides an overview of SDA use in the construction sector and examines development trends such as strength and durability. The findings indicate that implementing SDA into soi the soil stabilization sector benefits both sustainability and zero-waste technology. Environmental concerns about using SDA are also discussed, as are methods for minimizing the dangerous influence on the surrounding environment for future disaster risk reduction due to soil failure.
\end{abstract}

\section{Introduction}

The shortage of good quality soil suitable for construction and the recent emphasis on environmentally friendly mitigation strategies have prompted geotechnical engineering to explore and perfect systems for reusing excavated soils [1] and [2]. Preserving and improving existing pavements requires a sizable portion of transportation ministries' expenditures in every nation worldwide [3]. Approaches for lowering construction costs and extending the life of pavements can assist in better maintaining the transport system on a shoestring budget [4].

Roads constructed in the modern era are supposed to have a high standard of protection and comfort for their users [5]. Enhancement of soil can be accomplished through stabilization, modification, or combining the two [6]. While soil modification is accomplished by adding various admixtures such as lime or cement to alter the soil's index properties, soil stabilization is accomplished by treating the soil to increase its durability and strength to propose it is suitable for construction [7]. Soil stabilization is the process of modifying or adjusting the qualities of the soil to meet specific engineering requirements [8]. Compaction and the use of admixtures are two methods for soil stabilization. Lime and cement are two often used stabilizers for modifying the characteristics of soils.
Recent research suggests that solid wastes such as rice husk ash and fly ash can be used to stabilize soils in place of or in addition to cement or lime [9]. Saw dust is a by-product of the wood and lumber sawing sectors. Saw dust had limited cementitious value on its own. Still, when combined with water, it chemically interacts to generate cementitious compounds, which contribute to the increase of soil compressibility and strength parameter [10]. Silica is the prime component of saw dust ash (SDA), and it is responsible for the ash's reaction. Building technology is constantly evolving to accommodate changing transportation trends, building materials, and sub-grade conditions. The majority of pavement failures are due to the presence of poor subgrade conditions [1].

The industrial output of a wood manufacturing plant produces a variety of by-products. One of the majors is saw dust ash, produced when residue from wood chips, bark, sawdust, and cuts is used as an energy source [11]. The yearly production of saw dust ash is around 10,000 tons, but with increased production, the amount is approximately double. The created saw dust ash keeps gathering the mineral nutrients included in the waste wood, excluding nitrogen molecules, which are primarily discharged into the gaseous state during ignition. The nutrient mineral components present in solid compounds persist reasonably steady throughout the heat processing of combustion [12]. Specific components are in similar quantities as they were in the wood pulp composition, which is necessary for

* Corresponding author: r.munirwan@unsyiah.ac.id 
developing effective ways and technologies for utilizing the elements' chemo dynamic cycle in soil systems [13]. Nitrogen components from the wood are destroyed during the firing process and discharged into the environment as waste gases, primarily as oxides.

This research aims to briefly re-examine the effect of saw dust ash on soil stabilization and its reaction mechanism using extensive physicochemical and microanalysis. Additionally, the effects of ionic exchange on the mineralogy and microstructure of saw dust ashtreated soil are demonstrated convincingly. Finally, based on micro mechanisms and physicochemical observations, the strength behavior of SDA-treated soil is explored. Environmental friendly issue and future disaster risk reduction due to soil failure may be explained by using saw dust ash for soil stabilization and construction.

\section{Statement of problem}

The construction industry needs alternative and substitute alternatives for cement because of its price and pollution-prone manufacturing process. In addition, the cement industry accounts for around $7 \%$ of global $\mathrm{CO}$ emissions, with around $650-920 \mathrm{~kg} \mathrm{CO} 2$ released during the preparation of one ton of cement [14]. Thus, a product capable of reducing cement needs and the associated $\mathrm{CO}$ emission is an urgent requirement in the modern-day.

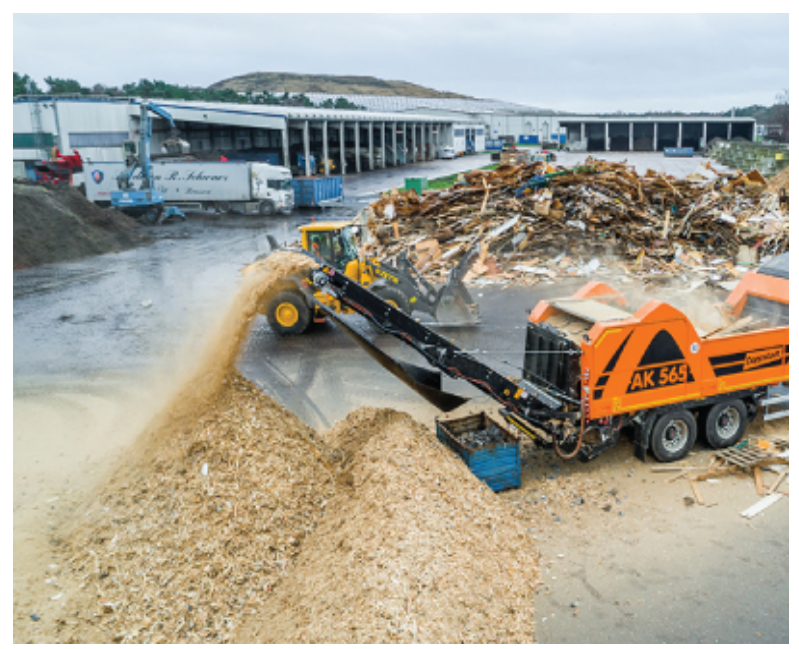

Fig. 1. Waste wood produced during manufacturing processing

An option to address the over-consumption of cement is to reduce the built environment's reliance on cement by including domestically available by-products as reinforcing cementitious and other low carbon components into the concrete manufacturing process [14]. Agricultural waste ashes, for example, rice husk ash (RHA) and palm oil fuel ash (POFA), have recently been investigated their use as construction material. Due to the high silica concentration, RHA becomes pozzolanic and can be used as a supplemental cementitious material in eco-concrete applications. Meanwhile, POFA has demonstrated significant potential as a cement substitute in concrete technology. Other agricultural waste ashes, such as coffee husk ash, sugarcane bagasse ash, corn cob ash, and saw dust ash, can be used as additions in building materials.

Agricultural wastes are typically incorporated into building in the form of ash. However, concerns about sustainable development and zero-waste innovation have prompted particular ashes as cement substitutes [15]. Currently, more than $70 \%$ of SDA is disposed of in the environment in a different structure. When some types of wood, such as chips and barks, are ignited, a substance termed SDA is formed. SDA is confined to specific specified dimensions necessary for optimal harvest development. SDA is produced globally through ignition in woodfired power plants, sawmills, paper mills, and other timber manufacturing processes.
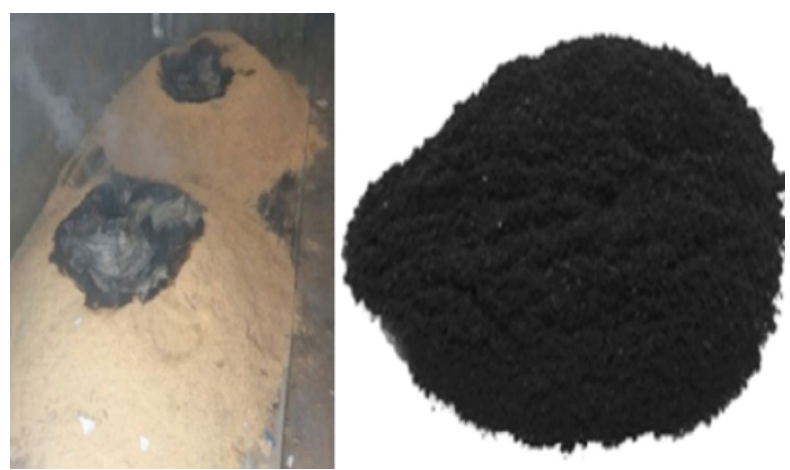

Fig. 2. Burning of saw dust and saw dust ash [5]

Between 1992 and 2010, the FAO stated that roughly $98.2 \times 10^{7} \mathrm{~m}^{3} \mathrm{SDA}$ was produced worldwide on an annual average basis [12]. China generated $15.3 \times 10^{\prime} \mathrm{m}^{3}$ of SDA during this period, followed by Brazil with $14 \mathrm{x}$ $10^{7} \mathrm{~m}^{3}$, the United States with $13 \times 10^{7} \mathrm{~m}^{3}$, the Federation of Russian with $7.9 \times 10^{7} \mathrm{~m}^{3}$, and France $7.7 \times 10^{7} \mathrm{~m}^{3}$. Wood waste generated during industrial processing can be seen in Fig 1.

Apart from all other ashes, SDA is developing into a more vibrant and nutrient-dense mass stream. SDA is primarily composed of destroyed wood and wastes from the wood industry; it is easy biomass and can also be referred to as a limitless fuel; hence, it is desirable for large-scale biomass ignition plants [18]. However, employing SDA as a substitute for conventional building materials has limitations. As a result, regulations on using SDA as a substitute for cement or lime in construction materials are necessary. Fig. 2 illustrates the process of combusting saw dust and the resulting saw dust ash.

Table 1. Chemical composition of wood ash

\begin{tabular}{|l|c|c|}
\hline \multirow{2}{*}{\multicolumn{1}{c|}{ Compound }} & \multicolumn{2}{c|}{ Composition (\%) } \\
\cline { 2 - 3 } & {$[16]$} & {$[17]$} \\
\hline Aluminum Oxide (A12O3) & 23.6 & 14.72 \\
Silicon Dioxide (SiO2) & 27 & 25.8 \\
Potassium Oxide (K2O) & 6.3 & 9.55 \\
Calcium Oxide (CaO) & 21.5 & 29.8 \\
Ferric Oxide (Fe2O3) & 2.7 & 0.95 \\
Magnesium Oxide (MgO) & 11 & 5.25 \\
Sodium Oxide (Na2O) & 7.9 & 7.5 \\
Loss on ignition, LOI & - & 2.7 \\
\hline
\end{tabular}




\section{Saw dust ash properties}

SDA comes in various chemical components, depending on the region in which it is produced and the combustion procedure used. Still, the principal oxides found in industrial SDA are mixed oxides, as illustrated in Table 1.

As illustrated in Fig. 3, the XRD data from [7] verified the presence of numerous main crystalline phases. Calcite $-\mathrm{CaCO}_{3}$ is the primary crystalline component, followed by quartz - $\mathrm{SiO}_{2}$ and potassium and calcium carbonate $-\mathrm{K}_{2} \mathrm{Ca}\left(\mathrm{CO}_{3}\right)_{2}$.

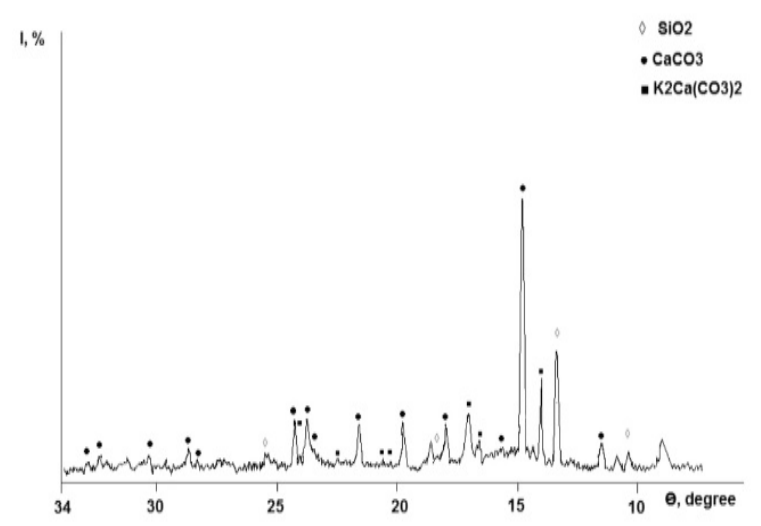

Fig. 3. Typical XRD pattern wood ash [7]

Fig. 4 illustrate SEM analysis of SDA as angular, brittle, and elongated granules with jagged edges of SDA from [11].

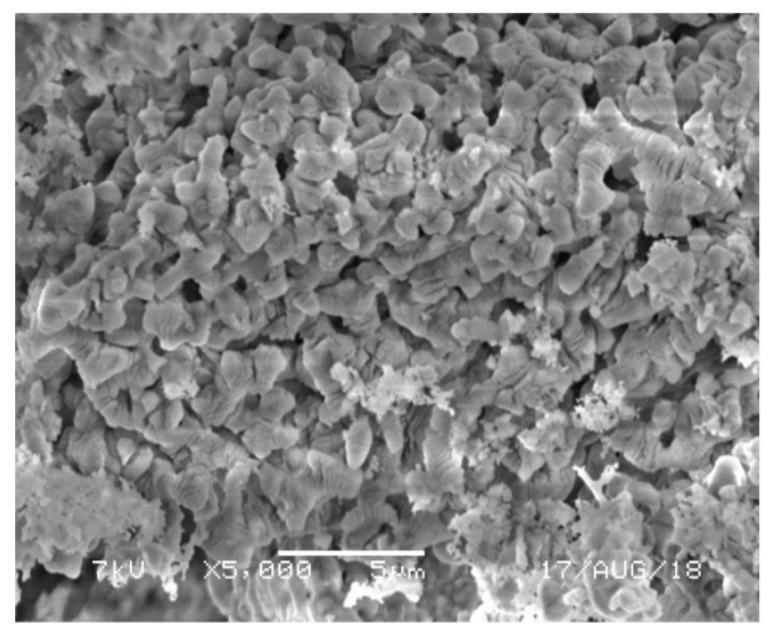

Fig. 4. Typical SEM of wood ash [11]

\section{Saw dust ash application}

Some research for applications of SDA utilization in road construction has been conducted in few past years. However, most of the SDA application is moderately effective to improve the physical and mechanical parameter of soil.

A comprehensive experimental investigation from [5] was conducted to evaluate SDA's soil improvement potential through CBR and UCS tests. The experimental analysis demonstrated that the inclusion of SDA increases the CBR and UCS significantly. Additionally, the CBR values obtained are within the suggested limits of Asphalt Institute for highway sub-base and sub-grade. Thereby, it is concluded from this study that SDA, an industrial waste, is a cost-effective stabilizing agent for road construction in clayey fills; however, its efficiency can be enhanced by integrating it with other bonding materials like lime, and thus becomes a viable alternative use of industrial waste to reduce road construction costs, especially in rural communities.

From [18], lateritic soil was treated with SDA by dry weight and compacted using the British Standard light compaction method to determine the chemical compatibility with landfill leachate municipal solid waste (MSW) in comparison to tap water. On treated soil specimens, index, compaction, and compatibility tests were conducted utilizing long-term hydraulic conductivity. The test findings indicate that hydraulic conductivity increased in the presence of permeation liquid. While hydraulic conductivity increased overall when test specimens were penetrated with MSW leachate, it dropped for samples treated for 4\% SDA but improved for all other treated samples compared to natural lateritic soil.

The effectiveness of wood ash as a stabilizing agent for soft clay has been examined by [17]. It is discovered that stabilizing existing soil improves the engineering features of the soil, specifically the UCS, shear strength parameters, workability, and compaction and compressibility properties. As a result, laboratory experiments on these parameters were conducted on a fixed amount of wood ash. Chemical analysis of wood ash reveals roughly $30 \%$ calcium oxide, which causes it to act similarly to a pozzolanic material. Additionally, the test result indicates that the soil might be made lighter by increasing its strength, moisture content, and compressibility with the addition of ash.

[11] examined the strength, stiffness, and microstructural response of marine-deposited clays in Cyprus modified with cement and wood-ash as a cement substitute. Portland cement $(7,10$, and $13 \%$ by weight) was substituted with varying amounts of wood ash (5 and $10 \%$ by weight) to produce concrete with two varied dry densities $\left(1400\right.$ and $\left.1600 \mathrm{~kg} / \mathrm{m}^{3}\right)$ and three different curing times (7, 28, and 60 days). UCS, porosity, direct shear, and pulse velocity testing were conducted. Additionally, SEM, XRD, and EDX studies were applied to characterize the microstructures of claywood-ash-cement mixes. The results indicated that substituting 5\% wood ash for cement resulted in higher performance. Further analysis of the microstructures of wood-ash-cement-clay blends revealed the creation of a porous matrix with stable linkages. Additionally, blends' porosity and strength qualities exhibit unique connections with their porosity and binder contents, as proven by other green substitute materials and soils.

The purpose of the research from [16] was to identify the optimal wood ash proportion for stabilizing black cotton soil. The laboratory study is designed to ascertain the soil sample's geotechnical properties. Wood ash is added in progressive mass percentages of $5 \%, 10 \%$, $15 \%$, and $20 \%$ per soil dry unit weight. Additionally, stabilized soils are cured for seven days for Atterberg limit and compaction tests and soaking for four days for CBR tests. Wood ash reduces the plasticity index, OMC, 
and swelling, according to an experimental study. On the other hand, adding wood ash can enhance CBR, maximum dry density, and UCS. The efficient wood ash ratio for stabilizing black cotton soil is between $10 \%$ and $15 \%$ of the soil mass, with a preference for results between $13 \%$ and $15 \%$.

\section{Conclusions}

SDA has the potential to be used as a substitute for soil stabilization in soil stabilization applications. SDA is capable of being used in large quantities. Numerous researches have examined a few key characteristics and demonstrated comparable strengths. Considerable progress has been made toward zero-waste technologies. SDA has been used in various amounts in the past for soil stabilization.

This brief review focused on the effect of SDA as a partial substitute for soil stabilization. SDA is regarded as additional source material or additive that increases the reactivity of binders. SDA-incorporated soil stabilization with various ashes, synthetic compounds, or filaments performed better than untreated soil. This behavior is mainly explained by the synergistic effects of SDA's pozzolanic and filler properties on the microstructure, resulting in a denser microstructure. As a result, by consolidating SDA in soil stabilization, the porous nature of the primary waste materials can be decreased.

\section{References}

1. R. P. Munirwan, M. Munirwansyah, M. Marwan, P. J. Ramadhansyah, and V. Kamchoom, IOP Conf. Ser. Mater. Sci. Eng. (2020)

2. M. Zhang, J. Yi, and D. Feng, Sci. Prog. 103, 1 (2020)

3. M. K. Atahu, F. Saathoff, and A. Gebissa, J. Rock Mech. Geotech. Eng. 11, 337 (2019)

4. C. C. Ikeagwuani and D. C. Nwonu, J. Rock Mech. Geotech. Eng. 11, 423 (2019)

5. W. A. Butt, K. Gupta, and J. N. Jha, Int. J. GeoEngineering (2016)

6. D. Sundary, R. P. Munirwan, and N. Al-Huda, J. Phys. Conf. Ser. (2021)

7. E. Serafimova, M. Mladenov, I. Mihailova, and Y. Pelovski, J. Univ. Chem. Technol. Metall. 46, 30 (2011)

8. D. S. Vijayan and D. Parthiban, Environ. Technol. Innov. 20, 101108 (2020)

9. M. Uduebor, O. J. Oyedepo, and O. B. Dorcas, J. Geotech. Transp. Eng. 5, 55 (2019)

10. B. Bunyamin, R. P. Munirwan, M. Ridha, and N. Hendrifa, IOP Conf. Ser. Mater. Sci. Eng. (2021)

11. A. Ekinci, M. Hanafi, and E. Aydin, Minerals (2020)

12. K. Tamanna, S. N. Raman, M. Jamil, and R. Hamid, Constr. Build. Mater. 237, (2020)

13. N. Ijaz, F. Dai, and Z. ur Rehman, J. Environ. Manage. 262, 110285 (2020)

14. D. Tavakoli, M. Hashempour, and A. Heidar, Pertanika J. Sci. Technol. 499 (2018)
15. Z. Sabzi, J. Environ. Friendly Mater. 2, 33 (2018)

16. S. S. Sefene, Geotech. Geol. Eng. (2020)

17. B. D. Nath, G. Sarkar, S. Siddiqua, M. Rokunuzzaman, and M. R. Islam, Adv. Civ. Eng. (2018)

18. K. J. Osinubi, A. O. Eberemu, J. R. Oluremi, and S. T. Ijimdiya, Proc. Inst. Civ. Eng. - Waste Resour. Manag. 1 (2017) 